University of Nebraska - Lincoln

DigitalCommons@University of Nebraska - Lincoln

Educational Psychology Papers and

Publications

Educational Psychology, Department of

2012

Self-Efficacy, Intrinsic Motivation, and Academic Outcomes

Among Latino Middle School Students Participating in an AfterSchool Program

\author{
Kate Niehaus \\ University of Louisville, kate.niehaus@sc.edu \\ Kathleen Moritz Rudasill \\ University of Nebraska-Lincoln, kmrudasill@vcu.edu \\ Jill L. Adelson \\ University of Louisville, jill.adelson@louisville.edu
}

Follow this and additional works at: https://digitalcommons.unl.edu/edpsychpapers

Part of the Child Psychology Commons, Cognitive Psychology Commons, Developmental Psychology Commons, and the School Psychology Commons

Niehaus, Kate; Rudasill, Kathleen Moritz; and Adelson, Jill L., "Self-Efficacy, Intrinsic Motivation, and Academic Outcomes Among Latino Middle School Students Participating in an After-School Program" (2012). Educational Psychology Papers and Publications. 156.

https://digitalcommons.unl.edu/edpsychpapers/156

This Article is brought to you for free and open access by the Educational Psychology, Department of at DigitalCommons@University of Nebraska - Lincoln. It has been accepted for inclusion in Educational Psychology Papers and Publications by an authorized administrator of DigitalCommons@University of Nebraska - Lincoln. 
Published in Hispanic Journal of Behavioral Sciences 34:I (2012), p. I I8-136;

doi: | 0.1 I 77/07399863 | |424275

Copyright (C) 2012 Kate Niehaus, Kathleen Moritz Rudasill, and Jill L.Adelson; published by SAGE Publications. Used by permission.

\title{
Self-Efficacy, \\ Intrinsic Motivation, \\ and Academic Outcomes \\ Among Latino Middle School \\ Students Participating in an \\ After-School Program
}

\section{Kate Niehaus,' Kathleen Moritz Rudasill, ${ }^{2}$ and Jill L. Adelson '}

I. University of Louisville, KY

2. University of Nebraska-Lincoln

Corresponding author - Kate Niehaus, Department Educational and Counseling Psychology, College of Education and Human Development, University of Louisville, Louisville, KY 40292; email kate.niehaus@louisville.edu

\begin{abstract}
This longitudinal study examined how academic self-efficacy, intrinsic motivation, and participation in an after-school program contributed to the academic achievement of Latino middle school students over the course of one school year. Participants were 47 Latino students in sixth through eighth grades who attended two public middle schools in which an after-school program was held that was specifically for Latino students. Results from ordinary least squares regression revealed that intrinsic motivation was positively associated with students GPAs, selfefficacy was a positive predictor of students' school attendance and standardized math achievement scores, and attendance at the afterschool program also contributed positively to students' math achieve-
\end{abstract}


ment. Results from multilevel growth modeling showed that students' self-efficacy and intrinsic motivation remained stable across the school year and were not related to students' degree of participation in the after-school program. Several avenues for future research within the Latino student population are discussed.

Keywords: Latino students, academic achievement, self-efficacy, intrinsic motivation, after-school program

Latino students are the largest and fastest-growing ethnic minority group in U.S. schools (U.S. Census Bureau, 2008), yet are at risk for a variety of negative academic outcomes (Cataldi, Laird, \& KewalRamani, 2009; Planty et al., 2009). Further complicating the unique struggles that Latino students face in school are the typical difficulties that all students experience during adolescence, particularly during the middle school years. Specifically, during the developmental period from sixth to eighth grade, students experience transitions in their school and social environments, a multitude of physical and emotional changes as they begin puberty, and significant declines in both self-concept and school performance (e.g., Alspaugh, 1998; Eccles, Lord, Roeser, \& Barber, 1997; Harter, 2006). Given that Latino adolescents are already at risk for school failure (Cataldi et al., 2009), the middle school years become even more important among this population in terms of planning prevention and intervention strategies.

Grade point averages (GPAs) and standardized test scores have long been considered benchmarks for judging students' academic success (Kuncel, Crede, \& Thomas, 2005). However, equally important are several internal characteristics (e.g., self-efficacy and motivation) that are highly related to school performance (Jinks \& Morgan, 1999; Lepper, Corpus, \& Iyengar, 2005). Thus, the present study focused on the interrelationships between academic outcomes, self-efficacy, and motivation among Latino middle schoolers participating in an after-school program designed to foster academic success. In addition, this study examined links between students' attendance at the after-school program (i.e., program dosage) and their academic outcomes and self-beliefs.

\section{Theoretical Foundations}

The importance of internal characteristics, such as self-efficacy and motivation, is supported by contemporary theories of human motivation, namely, 
self-determination theory (Deci \& Ryan, 2000). Deci and Ryan proposed that human behavior is motivated by three essential needs - competence, autonomy, and relatedness - all of which are important contributors to intrinsic motivation and psychological health. In addition, Deci and Ryan emphasized that individuals' environments play critical roles in determining the extent to which the needs of competence, autonomy, and relatedness are met. It is only when youth experience high-quality social environments that they can reach higher levels of performance and well-being.

The after-school program discussed in the present study featured several program components closely aligned with the tenets of self-determination theory (Deci \& Ryan, 2000). Because the program focused on academic tutoring and enrichment, students were given opportunities to practice new skills, learn from others, and receive positive feedback and recognition. Thus, several of the sources of self-efficacy proposed by Bandura (1997; i.e., mastery experiences, vicarious learning, and social persuasions) were incorporated into the program. Students were also given opportunities to choose activities in accordance with their interests and take ownership of the program to build feelings of autonomy. Lastly, to enhance interpersonal connections, program staff maintained communication with students' teachers and parents across the year, and students participated in group projects and social events. Thus, the purpose of the program was to create an environment that met students' psychological and social needs by promoting self-regulation of actions, interrelatedness with peers and adults, and feelings of personal efficacy and competence. These characteristics should, according to self-determination theory (Deci \& Ryan, 2000), foster students' sense of intrinsic motivation and ultimately promote academic success.

\section{Importance of Self-Efficacy}

Past research has consistently shown that students' beliefs about their abilities to successfully perform academic tasks (i.e., academic self-efficacy) predict their actual achievement levels in school (Bandura, 1997; Valentine, DuBois, \& Cooper, 2004). Overall, students with higher academic self-efficacy earn higher grades, set higher goals for themselves, and show greater effort and persistence in their work (Long, Monoi, Harper, Knoblauch, \& Murphy, 2007; Pajares, 2002). Though few studies of self-efficacy have been conducted with Latino samples, existing research suggests that academic self-efficacy is a predictor of school success for Latino students as well (Acoach \& Webb, 2004; Buriel, Perez, De Ment, Chavez, \& Moran, 1998). However, previous studies in this field (e.g., Acoach \& Webb, 2004; Buriel 
et al., 1998) have relied on students' self-reported grades as the only measure of achievement. This methodology is problematic in that self-reported grades are not as accurate as school records, and students with lower levels of school performance are even less reliable in reporting their grades (Kuncel et al., 2005). Thus, this study improves upon previous work by using a variety of academic measures obtained from school records.

\section{Importance of Motivational Orientation}

Intrinsic motivation is reflected in students who engage in activities because of their curiosity, interest, and enjoyment of learning, and a substantial body of research has demonstrated positive relationships between intrinsic motivation and academic achievement (e.g., Gottfried, Marcoulides, Gottfried, Oliver, \& Guerin, 2007; Lepper et al., 2005). Students with higher levels of intrinsic motivation also complete their homework more often, have higher educational aspirations, and have fewer school absences (Otis, Grouzet, \& Pelletier, 2005). Interestingly, previous research with Latino middle schoolers showed no relationship between intrinsic motivation and achievement (Unrau \& Schlackman, 2006), suggesting that motivation may share a different relationship with achievement among Latino adolescents. However, because so few studies have examined motivational orientation specifically within this population, further research needs to be conducted to clarify the nature of this motivation-achievement relationship for Latino students.

\section{Effectiveness of After-School Programs}

Although there is a large body of literature examining the effects of after-school programs on student achievement, results from these studies have yielded mixed results (Valentine, Cooper, Patall, Tyson, \& Civey Robinson, 2010). For example, several meta-analyses have shown that after-school programs have a positive effect on achievement (e.g., Durlak, Weissberg, \& Pachan, 2010; Lauer et al., 2006), whereas other meta-analytic work has shown after-school programs to have no effect on achievement (e.g., Bodilly \& Beckett, 2005; Zief, Lauver, \& Maynard, 2006). In addition, because the majority of work in this area has focused on students' academic outcomes (e.g., Lauer et al., 2006), less is known about how participation in afterschool programs may be related to more internal characteristics (e.g., motivation and self-efficacy). Burgeoning research with Latino samples suggests participation in after-school programs may be associated with academic gains for students (e.g., Riggs \& Greenberg, 2004), though there is not a 
broad enough literature base to draw conclusions about the benefits of afterschool programs for this population.

\section{Purpose of the Current Study}

Because little research has focused on self-efficacy, motivational orientation, and after-school program participation as possible correlates of Latino students' academic achievement in middle school, this study addresses a gap in the extant literature. Specifically, this study contributes to our growing knowledge in this field by addressing the following research questions:

Research Question 1: Do higher levels of academic self-efficacy, intrinsic motivation, and after-school program participation predict more positive academic outcomes for Latino students at the end of the school year (controlling for prior academic achievement)?

Research Question 2: Do Latino students experience changes in academic self-efficacy and intrinsic motivation over the course of 1 year in an afterschool program, and if so, does this differ by program attendance or prior academic achievement?

\section{Method}

\section{Program Description}

The after-school program was held in students' respective schools and met 1 day per week for 2.5 hour for the entire school year. The program was conducted by a nonprofit, community organization funded by 16 different agencies, including local government and business sponsors. The program was operated by two full-time staff members (the executive director and a volunteer), one teacher at each school who served as the liaison between the school and the program, and approximately 12 tutors from local high schools and a local university. All of these individuals were present at the program each week. The tutors were completing year-long service learning projects either for coursework or extracurricular organizations; thus, the same group of tutors worked with the students across the year. At the beginning of the year, each student was matched with a tutor, and the student-tutor pairs remained the same at each tutoring session, provided both individuals were present. The program staff also collaborated with the students' teachers throughout the year. Program staff tracked students' academic progress every 6 weeks using data provided by the school 
district, and they created specific tutoring plans for each student based on his or her academic progress, the core content being studied in his or her classes, and input from teachers. Classroom teachers would normally communicate with program staff (e.g., send additional worksheets or notes) via the liaison teachers.

The program included a variety of methods for recruiting students. Program staff met with teachers and counselors prior to the beginning of the school year to encourage them to refer students who may benefit from the program. Program staff also attended school events at the beginning of the year (e.g., "welcome night" for new students and "open house" events) to inform Latino families of the program. In addition, the program staff sent letters (in Spanish) to the parents of all Latino students attending these schools and enclosed preregistration forms for parents to indicate if they were interested. Phone calls were made to every family that expressed interest, and parents completed full registration forms for their children at the first program session of the year. Any Latino student attending one of these middle schools could enroll in the program with parental consent. There was no minimum GPA requirement; students only had to sign a behavioral contract in which they agreed to attend the program regularly, follow basic rules (e.g., respecting others), and strive for academic and personal growth. Parents also signed the behavioral contract agreeing to support their children's growth and signed a release of information form for the local school district (to track students' academic progress).

Regarding the structure of the after-school program, students maintained a consistent schedule each week. For the first 30 minutes of the program, students participated in some type of recreational activity (e.g., indoor or outdoor games). Students then had 15 minutes for snack time. For the next 30 minutes, students were given a writing prompt to which they responded in their journals. The writing prompt was different each week and was completed with the help of the tutors. For the last hour and 15 minutes, students worked with their tutors on homework assignments (students chose what they needed the most help with) or on other academic activities determined by program staff and teacher feedback.

\section{Participants}

Forty-seven Latino students enrolled in two middle schools in a large, urban public school district in the Midwestern United States participated in the after-school program, 19 of them at School A (an all-boys school) and 28 of them at School B (which served both boys and girls). Thirty-four participants $(72 \%)$ were males, and $13(28 \%)$ were females. The sample included 
students in sixth (19\%), seventh (34\%), and eighth (47\%) grades. Forty-four students $(94 \%)$ received free or reduced-price lunch, and for three students $(6 \%)$, this information was not reported. Thirty-one students $(66 \%)$ were first-generation immigrants to the United States (all from Mexico or Cuba), 11 students $(23 \%)$ were born in the United States, and for 5 students $(11 \%)$, this information was not reported. The majority of the students $(88 \%)$ were native Spanish speakers.

\section{Measures}

Demographic questionnaire. Students completed a personal information form that asked gender, age, date of birth, and grade level. There were four additional questions asking about birthplace, length of time living in the United States, native language, and the primary language spoken in the home.

Motivational orientation. The Intrinsic and Extrinsic Motivation Scale (IEMS) is a 30-item, self-report instrument that was administered to the students to assess motivational orientation (Lepper et al., 2005). The IEMS is divided into two subscales: the intrinsic motivation scale (17 items) and the extrinsic motivation scale (13 items). The IEMS is designed specifically for children and adolescents and requires respondents to use a 5-point Likerttype scale ranging from $0=$ not like me at all to $4=$ exactly like me. An example of one of the intrinsic motivation scale items reads, "I work on problems to learn how to solve them," whereas the comparable extrinsic motivation scale item states, "I work on problems because I'm supposed to" (Lepper et al., 2005, p. 187). Only the intrinsic motivation scale was used in the present study, which had acceptable levels of internal reliability in both Lepper et al.'s sample $(\alpha=.90)$ and in the present sample $(\alpha=.89)$.

Self-efficacy beliefs. Students also completed the Morgan-Jinks Student Efficacy Scale (MJSES), which is a 30-item self-report measure assessing students' academic self-efficacy (Jinks \& Morgan, 1999). Designed specifically for use with children and adolescents, this instrument consists of three subscales: talent, context, and effort. All 30 items from this instrument also can be averaged to calculate an academic self-efficacy composite score, the measure used in this study. Students respond to items on a 4-point Likert-type scale ranging from $0=$ really disagree to $3=$ really agree. Examples of items from the talent, context, and effort subscales are, respectively, "I am smart," "I will graduate from high school," and "I always get good grades when I try hard" (Jinks \& Morgan, 1999, p. 227). The composite scale had acceptable levels of internal reliability with Jinks and Morgan's sample $(\alpha=.82)$ and the present sample $(\alpha=.85)$. 
Program attendance. Students' attendance at the after-school program was measured by how many sessions they attended across the school year (ranged from 4 to 36 sessions with a mean of 14 sessions).

Academic outcomes. GPAs, standardized test scores for the current and previous school years (i.e., state accountability tests in reading and math), and school attendance were obtained through archival data maintained by the school district. GPAs were calculated on a scale of 0 (letter grade of $F$ ) to 4 (letter grade of $A$ ). School attendance was measured by how many days students were present across the school year. The state accountability tests in reading and math were the standardized achievement tests given to all public school students every spring. The achievement test scores ranged from 0 to 80 for every grade level. Because the test scores were not scaled across grade levels, the scores were transformed to represent each student's score relative to the proficiency cut point established by the state (40). To do so, the proficiency cut point was subtracted from each student's observed score. Thus, the values for the reading and math achievement variables ranged from -40 (40 points below proficiency) to +40 ( 40 points above proficiency). A score of 0 represents a student who scored exactly at the proficiency level.

\section{Procedure}

Because all of the participating students were Latino and a few were not fluent in English, the demographic questionnaire, IEMS, and MJSES were translated into Spanish by a professional translator and back-translated into English by the director of the after-school program, who was fluent in English and Spanish. Program staff identified only four students who were not fluent in English and needed the Spanish version of the survey. The majority of the students (92\%) were fluent in English and received the English version in all survey administrations.

Students completed the IEMS, the MJSES, and the demographic questionnaire at three time points across the 2009-2010 school year: fall (at the beginning of the program in September), winter (January), and spring (April). The procedures for survey administration were uniform across both schools. The same researcher performed all survey introductions, instructions, and administrations. Before passing out surveys, each student was assigned an identification number, the only identifying information on the survey packets. The IEMS was presented first with instructions provided by Lepper et al. (2005) for introducing this survey. After students finished the first survey, they were told to wait until everyone was finished before moving on to the second survey (i.e., the MJSES). Again, the researcher clearly ex- 
plained the questions and rating scale for the second survey. The researcher, the after-school program staff, and the tutors were present at each survey administration to help pass out survey packets and assist students in reading any unfamiliar words. Each survey administration lasted approximately 30 minutes.

\section{Missing Data}

To account for missing data, multiple imputation with Mplus statistical software (Muthen \& Muthen, 1998-2010) was used to impute 10 data sets, as recommended by Enders (2010). Values were imputed for the variables GPA, school attendance, Reading 2009, Reading 2010, Math 2009, Math 2010, intrinsic motivation (at Time 1, Time 2, and Time 3), and self-efficacy (at Time 1, Time 2, and Time 3). Data were missing for $14.1 \%$ of the possible 611 responses. The imputed datasets were then used to answer Research Questions 1 and 2 (see Table 1 for descriptive statistics for both the original and imputed data).

\section{Data Analysis}

Analyses were conducted using Mplus (Muthen \& Muthen, 1998-2010). For Research Question 1, which asked about the extent to which motivation, self-efficacy, and program attendance predicted academic outcomes, ordinary least squares (OLS) regression was conducted. For Research Question 2 , which asked about the extent to which students' intrinsic motivation and academic self-efficacy changed across the school year, the data featured observations within students. Therefore, multilevel growth models were analyzed with full maximum likelihood estimation. Because the data contained only three observations per student, analyses were limited to linear growth models only (Raudenbush \& Bryk, 2002), which was appropriate given the shape of the trajectories as determined by individual and overall graphs.

\section{Results}

\section{Research Question I}

All outcome variables were regressed on intrinsic motivation (Time 1), self-efficacy (Time 1), and program attendance. To control for students' prior academic achievement, Reading 2009 was used as a control variable in the GPA, school attendance, and reading achievement analyses, while Math 2009 was controlled for in the math achievement model. ${ }^{1}$ 
Table I. Means and Standard Deviations for Original and Imputed Data

\begin{tabular}{|c|c|c|c|c|c|c|}
\hline \multirow[b]{2}{*}{ Variable } & \multicolumn{3}{|c|}{ Original data } & \multicolumn{3}{|c|}{ Imputed data } \\
\hline & $N$ & M & $S D$ & $N$ & M & $S D$ \\
\hline GPA & 45 & 2.53 & 0.68 & 47 & 2.56 & 0.69 \\
\hline Reading 2009 & 40 & -3.25 & 19.13 & 47 & -3.76 & 19.66 \\
\hline Reading 2010 & 44 & -1.77 & 20.41 & 47 & -1.85 & 20.56 \\
\hline Math 2009 & 40 & -7.50 & 19.70 & 47 & -6.90 & 20.78 \\
\hline Math 2010 & 44 & -14.14 & 18.13 & 47 & -13.79 & 19.11 \\
\hline School attendance & 44 & 160.91 & 11.62 & 47 & 161.00 & 11.35 \\
\hline Program attendance & 47 & 14.38 & 7.09 & 47 & 14.38 & 8.77 \\
\hline \multicolumn{7}{|l|}{ Intrinsic motivation } \\
\hline Fall & 41 & 2.39 & 0.76 & 47 & 2.42 & 0.97 \\
\hline Winter & 32 & 2.24 & 0.82 & 47 & 2.08 & 0.87 \\
\hline Spring & 37 & 2.31 & 0.65 & 47 & 2.34 & 0.84 \\
\hline \multicolumn{7}{|l|}{ Self-efficacy } \\
\hline Fall & 41 & 2.01 & 0.40 & 47 & 2.00 & 0.39 \\
\hline Winter & 32 & 2.12 & 0.38 & 47 & 2.09 & 0.41 \\
\hline Spring & 37 & 2.10 & 0.41 & 47 & 2.08 & 0.44 \\
\hline
\end{tabular}

$\mathrm{GPA}=$ grade point average .

GPA. The model explained approximately $36 \%$ of the variability in students' GPA $\left(R^{2}=.36, p=.001\right)$. After controlling for students' prior reading achievement $(\beta=.40, p=.002)$, students who had higher intrinsic motivation at the beginning of the school year had higher GPAs at the end of the year ( $\beta$ $=.32, p=.01)$. There were positive, but statistically nonsignificant, relationships between program attendance and GPA $(\beta=.15, p=.24)$ as well as selfefficacy and GPA $(\beta=.20, p=.14)$.

School attendance. The four predictor variables accounted for $27 \%$ of the variance in students' school attendance $\left(R^{2}=.27, p=.02\right)$. After controlling for students' prior reading achievement $(\beta=-.17, p=.25)$, students who had higher self-efficacy at the beginning of the school year attended more days of school throughout the year $(\beta=.55, p<.001)$. Neither program attendance $(\beta=.05, p=.74)$ nor intrinsic motivation $(\beta=-.15, p=.25)$ was statistically significantly associated with students' school attendance.

Reading achievement. The regression model explained approximately $59 \%$ of the variability in students' reading achievement scores $\left(R^{2}=.59, p<\right.$ $.001)$. However, after controlling for students' prior reading achievement $(\beta$ $=.65, p<.001)$, neither program attendance $(\beta=.08, p=.42)$, intrinsic mo- 
tivation $(\beta=-.002, p=.99)$, nor self-efficacy $(\beta=.18, p=.25)$ was a statistically significant predictor of students' reading achievement scores.

Math achievement. The four predictor variables accounted for $75 \%$ of the variance in students' math achievement scores $\left(R^{2}=.75, p<.001\right)$. After controlling for previous math achievement $(\beta=.52, p<.001)$, students who had higher self-efficacy at the beginning of the year $(\beta=.39, p=.01)$ and attended the after-school program more frequently $(\beta=.20, p=.02)$ achieved higher scores on the end-of-year standardized math assessment. Intrinsic motivation $(\beta=-.11, p=.22)$ was not statistically significantly related to students' math achievement.

\section{Research Question 2}

For the growth models, program attendance was grand mean centered. Reading 2009 and Math 2009 were entered into the model uncentered, because both variables already had a meaningful zero. Time was centered at the spring data collection, such that fall was coded as -2 , winter was coded as -1 , and spring was coded as 0 . By centering time at the spring data collection, the focus of the data analysis was examining students' levels of motivation and self-efficacy at the end of the school year after a full year of participation in the after-school program. The intercept (i.e., students' scores at the end of the year) and growth slope (i.e., students' degree of change per semester) were allowed to randomly vary across students. The following equations were used to estimate the full models for intrinsic motivation and self-efficacy.

Level 1 model:

$$
\mathrm{Y}_{\mathrm{ti}}=\pi_{0 \mathrm{i}}+\pi_{1 \mathrm{i}}(\text { Time_Spring })_{\mathrm{ti}}+\mathrm{e}_{\mathrm{ti}}
$$

Level 2 model:

$$
\begin{gathered}
\pi_{0 \mathrm{i}}=\beta_{00}+\beta_{01}(\text { Program Attendance })+\beta_{02} \text { (Prior Reading) } \\
+\beta_{03} \text { (Prior Math) }+\mathrm{r}_{0 \mathrm{i}} \\
\pi_{1 \mathrm{i}}=\beta_{10}+\beta_{11}(\text { Program Attendance })+\beta_{12} \text { (Prior Reading) } \\
+\beta_{13} \text { (Prior Math) }+\mathrm{r}_{1 \mathrm{i}}
\end{gathered}
$$

Intrinsic motivation. Results from the full model showed that students had an average intrinsic motivation score of 2.43 points at the end of the school year, after controlling for program attendance and prior reading and math achievement. None of the individual level 2 predictors (i.e., program attendance, Reading 2009, Math 2009) were statistically significant predic- 
tors of students' end-of-year intrinsic motivation scores. In fact, the between-person variability in the end-of-year intrinsic motivation scores was still statistically significant in the full model $\left(\tau_{00}=.70, p=.046\right)$, meaning that significant variability among students remains to be explained by variables not in the present model. Results for the growth slope revealed that students' levels of intrinsic motivation remained stable per semester $\left(\beta_{10}=\right.$ $.02, p=.66$ ), regardless of program attendance or prior achievement levels. There was no significant variability between students in their semester growth rates $\left(\tau_{11}=.07, p=.57\right)$.

Self-efficacy. Results from the full model showed that students had a mean self-efficacy score of 2.27 points at the end of the school year, holding program attendance and prior achievement constant. Students with higher prior math achievement had higher self-efficacy at the end of the year $\left(\beta_{03}=.01, p\right.$ $=.045)$. Neither program attendance nor prior reading achievement was associated with end-of-year self-efficacy. Students did not show statistically significant changes in their self-efficacy scores per semester $\left(\beta_{10}=.15, p=.12\right)$, and this did not differ based on any of the predictor variables. There was still statistically significant variability between students' end-of-year self-efficacy scores $\left(\tau_{00}=.20, p=.002\right)$ and their semester growth rates $\left(\tau_{11}=.06, p=.01\right)$ that remains to be explained by variables not in the model.

\section{Discussion}

In the present study of Latino students participating in an after-school program, five main findings emerged: (1) Self-efficacy was a significant predictor of students' math achievement and school attendance, (2) intrinsic motivation positively predicted students' GPAs, (3) students who attended the after-school program more often achieved higher scores on the end-of-year standardized math assessment, (4) students' levels of motivation and self-efficacy remained stable across the year and were not statistically significantly related to the number of days they attended the after-school program (i.e., dosage), and (5) students differed from one another in their motivation and self-efficacy at the end of the year, yet such differences were unexplained by variables in the current study. Each of these findings is discussed below, along with implications of the results and suggestions for future research.

Results from this study were consistent with previous research in suggesting that academic self-efficacy is an important contributor to positive academic outcomes for Latino students (Acoach \& Webb, 2004; Buriel et al., 
1998). In addition, this study extended previous studies with Latino populations by using a variety of academic outcomes as reported on school records. Indeed, students who had higher self-efficacy attended school more frequently across the year and achieved higher scores on the end-of-year standardized math assessment, even after controlling for prior academic performance. Thus, results point to the importance of fostering self-efficacy for Latino students during the middle school years by helping Latino students believe that they are capable of completing academic tasks and reaching desired goals at school. Findings also illustrate that Latino students' self-beliefs are an important construct to consider when examining academic outcomes and that it is important to explore what variables at home and school may contribute to such beliefs.

Interestingly, while self-efficacy was not a statistically significant predictor of students' GPAs, intrinsic motivation was. Specifically, students who were more intrinsically motivated earned higher grades. These findings suggest that Latino middle schoolers who are more interested in their schoolwork, who enjoy learning new and challenging information, and who have mastery goals to accomplish school tasks (Lepper et al., 2005) are more successful in their classes. Intrinsic motivation was not associated with students' performance on standardized achievement tests, which is consistent with previous work by Unrau and Schlackman (2006) when studying Latino students. This is likely due to the fact that intrinsic motivation is linked with positive academic behaviors (e.g., homework completion, higher educational aspirations; Otis et al., 2005) that contribute to students' effort and performance in the classroom but may not necessarily be correlated with high-stakes testing outcomes. However, given that motivation was important for students' grades and that few researchers have examined motivation among Latino adolescents, this study highlights the importance of students' interest and engagement in their schoolwork during this developmental period.

Another important finding that emerged from the study was that students who attended the after-school program more often achieved higher scores on the standardized math test. The after-school program included skill-building exercises or games related to math during its regular program activities, and students spent at least an hour in individual tutoring each session in which they often focused on math homework. Thus, findings suggest that students who spent more time involved in these academic activities were achieving at higher levels in math, even after controlling for their prior achievement in this subject. Although this was not an experimental study and no claims can be made regarding causality, this is an encouraging finding in that students' degree of participation in the after- 
school program was positively linked with their math achievement. These findings are even more striking when considering that the students received such a low dosage (i.e., 2.5 hours per week) of the program. If a higher dosage of the intervention were offered (e.g., 5 to 10 hour per week), results may point to additional benefits for students. This question, however, warrants further research, preferably with a randomized control trial (RCT) design and a larger sample of students and schools.

Growth analyses showed that students' levels of intrinsic motivation and self-efficacy remained stable across the year, and there was no relationship between students' attendance at the after-school program and their motivation and self-efficacy. Results from this study suggest that Latino students' levels of participation in an after-school program may be more related to actual academic performance (i.e., math achievement) as compared to less observable, internal characteristics (i.e., motivation and efficacy beliefs). One possible explanation for this finding is that though students' self-beliefs (e.g., self-esteem; Robins \& Trzesniewski, 2005) and their motivation levels (e.g., Gottfried, Fleming, \& Gottfried, 2001) decline from childhood into adolescence, they also become increasingly stable and resistant to change. Thus, it is more difficult to modify such internal characteristics in middle or high school than it would be during the elementary school years. This leaves the question as to whether after-school programming or other academic interventions would be more effective in targeting Latino students' self-beliefs and motivational levels if implemented at an earlier stage of development (e.g., early to middle childhood). Again, this would be an interesting arena for future research, to ensure that academic intervention programs are reaching their maximum levels of effectiveness in terms of helping Latino students believe and take interest in their academic abilities.

Interestingly, in the present study, there was significant variability between students in their levels of motivation and self-efficacy at the end of the year, but none of the variables examined in this study could explain such differences (with the exception of prior math achievement predicting self-efficacy). Thus, further research is needed. It could be that variables related to Latino students' home lives (e.g., parenting styles, cultural values), extracurricular activities (e.g., sports and clubs), or school environments (e.g., relationships with teachers and peers) are more important to their motivational orientation and efficacy beliefs. This possibility needs to be investigated further, as little is currently known about the nature of motivation and self-efficacy among Latino adolescents. Given that intrinsic motivation and self-efficacy were significant predictors of students' academic success in the present study, future studies should examine what types of variables at both the stu- 
dent and school levels can contribute to more positive self-beliefs and stronger motivation among this population of students.

\section{Limitations}

There were several limitations in the present study, most important of which was the small sample size. This was the only after-school program specifically for Latino students in the geographic area, and therefore, it was not possible to expand the sample to include other students or schools involved in a similar program. However, the small sample reduced statistical power to detect small effect sizes and potentially limited the extent to which findings generalize to other Latino students in different schools and geographic areas. For both of these reasons, a larger study is needed. In addition, this was not an experimental study that allowed for intervention-control group comparisons. The main focus of this study was examining associations between student characteristics and achievement among an under-researched group of students participating in a specialized program. In terms of assessing the relationships between after-school program participation and academic outcomes, the inconsistency in students' program attendance was also a limitation. Students' attendance in the fall semester $(M=8.77)$ was higher than in the spring semester $(M=5.62)$, indicating that many students began the school year with strong attendance but participated less frequently as the year progressed. This could be due to a variety of reasons, including more enthusiasm at the beginning of a new school year, increased participation in other after-school activities as the year progressed, and involvement with spring sports (e.g., several students were on the baseball team). Regardless of the reasons for students' inconsistent attendance, we would have been better able to evaluate the link between program participation and student outcomes had students attended the program on a more regular basis across the entire year.

\section{Conclusions}

Given that Latino students are at an increased risk of academic failure (Cataldi et al., 2009), findings from the current study are important in highlighting the positive contributions of self-efficacy, intrinsic motivation, and participation in an after-school program to various academic outcomes for Latino middle schoolers. The present study also revealed many areas of future research, particularly related to after-school programming for this population of students and further examination of variables that may foster stu- 
dents' self-beliefs and motivation. As the Latino school-aged population continues to grow, it will become increasingly important to identify factors that contribute to their academic success, which may potentially provide avenues for additional prevention and intervention strategies in our schools and communities.

Acknowledgment - The authors would like to thank the students and program staff, particularly the director of the after-school program, who were involved in data collection. In addition, we are grateful to several individuals in the school system's research and planning office who helped gather archival data from student records.

\section{Note}

1. We also conducted each regression analysis using a median split on program attendance to determine whether there were differences between students attending less than the median number of sessions and students attending the median number of sessions or more. Results from these analyses were highly similar to the findings reported here using program attendance as a continuous variable.

\section{References}

Acoach, C., \& Webb, L. (2004). The influence of language brokering on Hispanic teenagers' acculturation, academic performance, and nonverbal decoding skills: A preliminary study. The Howard Journal of Communications, 15, $1-19$.

Alspaugh, J. (1998). Achievement loss associated with the transition to middle school and high school. Journal of Educational Research, 92, 20-25.

Bandura, A. (1997). Self-efficacy: The exercise of control. New York, NY: Freeman.

Bodilly, S., \& Beckett, M. (2005). Making out of school time matter: Evidence for an action agenda. Santa Monica, CA: RAND Corporation.

Buriel, R., Perez, W., De Ment, T., Chavez, D., \& Moran, V. (1998). The relationship of language brokering to academic performance, biculturalism, and self-efficacy among Latino adolescents. Hispanic Journal of Behavioral Sciences, 20, 283-297.

Cataldi, E., Laird, J., \& KewalRamani, A. (2009). High school dropout and completion rates in the U.S.: 2007 compendium report (NCES 2009-064). Washington, DC: U.S. Department of Education, National Center for Education Statistics. 
Deci, E., \& Ryan, R. (2000). The "what" and "why" of goal pursuits: Human needs and the self-determination of behavior. Psychological Inquiry, 11, 227-268.

Durlak, J., Weissberg, R., \& Pachan, M. (2010). A meta-analysis of after-school programs that seek to promote personal and social skills in children and adolescents. American Journal of Community Psychology, 45, 294-309.

Eccles, J., Lord, S., Roeser, R., \& Barber, B. (1997). The association of school transitions in early adolescence with developmental trajectories through high school. In J. Schulenberg, J. Maggs, \& K. Hurrelmann (Eds.), Health risks and developmental transitions during adolescence (pp. 283-320). New York, NY: Cambridge University Press.

Enders, C. (2010). Applied missing data analysis. New York, NY: Guildford.

Gottfried, A., Fleming, J., \& Gottfried, A. (2001). Continuity of academic intrinsic motivation from childhood through late adolescence: A longitudinal study. Journal of Educational Psychology, 93, 3-13.

Gottfried, A., Marcoulides, G., Gottfried, A., Oliver, P., \& Guerin, D. (2007). Multivariate latent change modeling of developmental decline in academic intrinsic math motivation and achievement: Childhood through adolescence. International Journal of Behavioral Development, 31, 317-327.

Harter, S. (2006). The self. In W. Damon (Editor-in-Chief) \& N. Eisenberg (Vol. Ed.), Handbook of child psychology. Vol. 3: Social, emotional, and personality development (6th ed., pp. 505-570). New York, NY: John Wiley.

Jinks, J., \& Morgan, V. (1999). Children's perceived academic self-efficacy: An inventory scale. The Clearing House: A Journal of Educational Research, Controversy, and Practices, 72, 224-230.

Kuncel, N., Crede, M., \& Thomas, L. (2005). The validity of self-reported grade point averages, class ranks, and test scores: A meta-analysis and review of the literature. Review of Educational Research, 75, 63-82.

Lauer, P., Akiba, M., Wilkerson, S., Apthorp, H., Snow, D., \& Martin-Glenn, M. (2006). Out-of-school-time programs: A meta-analysis of effects for at-risk students. Review of Educational Research, 76, 275-313.

Lepper, M., Corpus, J., \& Iyengar, S. (2005). Intrinsic and extrinsic motivational orientations in the classroom: Age differences and academic correlates. Journal of Educational Psychology, 97, 184-196.

Long, J., Monoi, S., Harper, B., Knoblauch, D., \& Murphy, P. (2007). Academic motivation and achievement among urban adolescents. Urban Education, 42, 196-222.

Muthen, L., \& Muthen, B. (1998-2010). Mplus user's guide (6th ed.). Los Angeles, CA: Muthen \& Muthen. 
Otis, N., Grouzet, M., \& Pelletier, L. (2005). Latent motivational change in an academic setting: A 3-year longitudinal study. Journal of Educational Psychology, 97, 170-183.

Pajares, F. (2002). Gender and perceived self-efficacy in self-regulated learning. Theory Into Practice, 41, 116-225.

Planty, M., Hussar, W., Snyder, T., Kena, G., KewalRamani, A., Kemp, J., . . . Dinkes, R. (2009). The condition of education 2009 (NCES 2009-081). Washington, DC: U.S. Department of Education, National Center for Education Statistics.

Raudenbush, S., \& Bryk, A. (2002). Hierarchical linear models (2nd ed.). Thousand Oaks, CA: SAGE.

Riggs, N., \& Greenberg, M. (2004). Moderators in the academic development of migrant Latino children attending after-school programs. Journal of Applied Developmental Psychology, 25, 349-367.

Robins, R., \& Trzesniewski, K. (2005). Self-esteem development across the lifespan. Current Directions in Psychological Science, 14, 158-162.

Unrau, N., \& Schlackman, J. (2006). Motivation and its relationship with reading achievement in an urban middle school. The Journal of Educational Research, 100, 81-101.

U.S. Census Bureau. (2008). An older and more diverse nation by mid-century. Retrieved October 12, 2008, from http://www.census.gov/Press-Release/ www.releases/archives/population/012496.html

Valentine, J., Cooper, H., Patall, E., Tyson, D., \& Civey Robinson, J. (2010). A method for evaluating research syntheses: The quality, conclusions, and consensus of 12 syntheses of the effects of after-school programs. Research Synthesis Methods, 1, 20-38.

Valentine, J., DuBois, D., \& Cooper, H. (2004). The relation between self-beliefs and academic achievement: A meta-analytic review. Educational Psychologist, 39, 111-133.

Zief, S., Lauver, S., \& Maynard, R. (2006). Impacts of after-school programs on student outcomes. Campbell Systematic Reviews, 3, 1-56. 


\section{About the authors}

Kate Niehaus is a doctoral candidate in the Educational Psychology, Measurement, and Evaluation program at the University of Louisville. Her primary research interests involve: (a) the academic achievement and self-perceptions of English Language Learners and Latino students, and (b) the role of school support and students' feelings of school connectedness in predicting academic and behavioral outcomes. She currently teaches courses in human development and learning at the University of Louisville.

Kathleen Moritz Rudasill is an associate professor of educational psychology at the University of Nebraska-Lincoln. She earned her doctorate from the University of Virginia in 2006 where she was an Institute of Education Sciences predoctoral fellow. Her research is focused on understanding individual and contextual factors that influence children's academic and social outcomes, with particular emphasis on how classroom processes mediate and moderate associations between children's characteristics and their success in school.

Jill L. Adelson is an assistant professor in the Educational Psychology, Measurement, and Evaluation program in the Department of Educational and Counseling Psychology at the University of Louisville. She received her $\mathrm{PhD}$ from the University of Connecticut in measurement, evaluation, and assessment and in gifted education. Her research involves applying and studying advanced methodologies, such as HLM and SEM. Her substantive research interests include the effects of gifted programming, the talent development of mathematically talented elementary students, and attitudes toward mathematics. 